\title{
Screening of antioxidant and antidepressant activity of Vanda tessellata leaves extract
}

\author{
Bindiya Prakash ${ }^{1 *}$, Ritu Thakur Bais ${ }^{2}$, Ram Kumar Sahu ${ }^{3}$
}

${ }^{1}$ Department of Botany, Sarojini Naidu Government Girls Post Graduate (Autonomous) College, Shivaji Nagar, Bhopal, Madhya Pradesh, India, ${ }^{2}$ Department of Botany, Government Maharani Laxmi Bai Girls Post Graduate (Autonomous), College, Bhopal, Madhya Pradesh, India, ${ }^{3}$ University College of Pharmacy, Pt. Deendayal Upadhyay Memorial Health Sciences and Ayush University of Chhattisgarh, Raipur, Chhattisgarh, India

\section{Abstract}

Aim: Vanda tessellata is an endangered orchid of high medicinal value plant containing flavonoid and polyphenol components. The present study was aimed to evaluate the antioxidant and antidepressant activity of leaves extract of $V$. tessellata. Materials and Methods: The chloroform and ethanol extracts were prepared from V. tessellata leaves. The total phenolic content and total flavonoid content were determined for antioxidant activity of extracts. Antidepressant activity was identified using a modified forced swimming test (FST) and tail suspension test (TST). Results and Discussion: The total phenolic content of chloroform and ethanol extracts of $V$. tessellate were $98.25 \pm 0.11$ and $202.00 \pm 0.21$ gallic acid equivalent $\mathrm{mg} / \mathrm{gm}$, respectively. The concentrations of flavonoids in chloroform and ethanol extracts of $V$. tessellate were $23.57 \pm 0.47$ and $114.48 \pm 0.12$ quercetin equivalent $\mathrm{mg} / \mathrm{gm}$, respectively. The ethanol extract demonstrated significant antidepressant activity by a reduction in immobility times of rats in TST and FST. Conclusion: The findings concluded that the antidepressant activity of $V$. tessellate extracts may be due to the presence of polyphenol and flavonoids.

Key words: Total flavonoid content, total phenolic content, vanda tessellata

\section{INTRODUCTION}

$\mathrm{R}$ eactive oxygen species (ROS)/free radicals are a vital risk factor in the development of various chronic diseases. ROS are renowned as agents involved in the pathogenesis of $>100$ diseases including asthma, diabetes, inflammation, cancer, depression disorders, atherosclerosis, liver cirrhosis, immunosuppression, and nephrotoxicity. The numerous previous studies demonstrated that ROS are also responsible for human aging. ROS are innumerable forms of activated oxygen such as superoxide anion radicals and hydroxyl radicals.

An imbalance between ROS and the inherent antioxidant capacity of the body suggested using of dietary and/or medicinal supplements. Previous studies indicated that fruits, vegetables, and plants are the main source of antioxidant in the diet. The antioxidants compound such as phenolics, flavonoids, tannins, and proanthocyanidins scavenge free radicals such as peroxide, hydroperoxide, or lipid peroxyl and thus inhibit the oxidative mechanisms that lead to degenerative diseases. Natural antioxidants may have free-radical scavengers, reducing agents, complexes of pro-oxidant metals, quenchers of singlet oxygen, etc. Natural antioxidants either in the form of raw extracts or their chemical constituents are very effective to prevent the destructive processes caused by oxidative stress. It has been documented by researchers that medicinal plants are considered as a good antioxidant since prehistoric times. ${ }^{[1-3]}$

Depression is a neurological disorder that leads to changes in mood, thoughts, behavior, and physical health. It is reported that $21 \%$ of the global population affects from depression. Depression can happen at any age groups from

Address for correspondence:

Bindiya Prakash, Department of Botany, Sarojini Naidu Government Girls Post Graduate (Autonomous) College, Shivaji Nagar, Bhopal, Madhya Pradesh, India.

Phone: +91-8120718626.

E-mail: prakashbindiya32@gmail.com

Received: $19-07-2018$

Revised: $11-10-2018$

Accepted: 04-11-2018 
childhood to later life. It is estimated that $>20 \%$ of the adult population undergoes from these conditions at least some time in their lifetime. The world health organization expects that depression will become the second leading cause of premature death or disability all over the world by the year 2020. At present, synthetic drug prescribed for depression is expensive and associated with various side effects, namely body weight gain, cardiac toxicity, and sexual dysfunction. There is emergent interest in the use of herbal medicines for the management of depressive disorders due to the minimum side effect and economic. ${ }^{[4-7]}$

Among the various medicinal plants, Vanda tessellata is one such orchid having a number of medicinal properties. It is an epiphytic orchid. Vanda tessellate plants have been used in indigenous medicine such as Ayurveda and local traditional medical practices. The different pharmacological properties such as anti-inflammatory, anticonvulsant, hepatoprotective, antidiarrheal, and aphrodisiac properties of $V$. tessellate have been reported. The phytochemical screening of $V$. tessellata has exhibited an alkaloid, sitosterol, resin, saponin, polyphenol, flavonoids, tannins, fatty acids, coloring agents, etc. ${ }^{[8-11]}$ Hence, the present study was designed to evaluate the antioxidant and antidepressant activity of leaves extract of $V$. tessellata.

\section{MATERIALS AND METHODS}

\section{Plant Material}

The leaves of $V$. tessellata were selected for the proposed study. The leaves were shade dried, reduced to coarse powder and stored in an airtight container until further use.

\section{Preparation of Extract}

The powdered leaves of $V$. tessellate about $500 \mathrm{~g}$ were packed in Soxhlet apparatus and extracted with successively with chloroform and ethanol, until the completion of the extraction. The extract was filtered while hot, and the resultant extract was distilled in vacuum under reduced pressure to remove the solvent completely, and later dried in a desiccator.

\section{Total Polyphenol Content}

Total polyphenol content was determined using the colorimetric method. $1.0 \mathrm{ml}$ of the prepared extract was oxidized using $2.5 \mathrm{ml}$ of Folin-Ciocalteu reagent, and $2.0 \mathrm{ml}$ of sodium carbonate solution $(75 \mathrm{~g} / \mathrm{l})$ was then added to the reaction mixture. The absorbance readings were taken at $760 \mathrm{~nm}$ after incubation at room temperature for $2 \mathrm{~h}$. The amount was calculated using the gallic acid calibration curve. The results were expressed as gallic acid equivalent (GAE) mg per $100 \mathrm{ml}$ of the sample (extract).

\section{Calibration curves of gallic acid}

Accurately weighed $100 \mathrm{mg}$ of gallic acid was dissolved in $100 \mathrm{ml}$ of distilled water which gives the concentration of $1000 \mu \mathrm{g} / \mathrm{ml}$. $10 \mathrm{ml}$ of this solution was taken and made up to $100 \mathrm{ml}$ with gallic acid which contains the concentration of $100 \mu \mathrm{g} / \mathrm{ml}$. Further, $25 \mathrm{ml}$ of this solution was taken and made up to $100 \mathrm{ml}$ with quercetin which contains the concentration of $25 \mu \mathrm{g} / \mathrm{ml}$. Similarly, 50, 75, 100, 125, and $150 \mu \mathrm{g} / \mathrm{ml}$ concentrations of gallic solution were prepared. Calibration curve was plotted by mixing $1 \mathrm{ml}$ aliquots of gallic acid solutions with $2.5 \mathrm{ml}$ of Folin-Ciocalteu reagent and $2.0 \mathrm{ml}$ of sodium carbonate solution $(75 \mathrm{~g} / 1)$. The absorbance was measured after incubation at room temperature for $2 \mathrm{~h}$ at $760 \mathrm{~nm}$ using Ultraviolet (UV) spectrophotometer, against the blank solution.

\section{Total Flavonol Content}

Flavones and flavonols contents were analyzed by the colorimetric method. $9.8 \mathrm{ml}$ of the prepared extract was mixed with a $10 \%$ solution of aluminum chloride $(200 \mu \mathrm{l})$. After $30 \mathrm{~min}$, absorption was measured at a $425 \mathrm{~nm}$ wavelength. The amount was calculated using quercetin calibration curve. The results were expressed as the quercetin equivalent $(\mathrm{QE})$ mg per $100 \mathrm{ml}$ of the sample.

\section{Calibration curves of Quercetin}

Accurately weighed $100 \mathrm{mg}$ of quercetin was dissolved in $100 \mathrm{ml}$ of distilled water which gives the concentration of $1000 \mu \mathrm{g} / \mathrm{ml} .10 \mathrm{ml}$ of this solution was taken and made up to $100 \mathrm{ml}$ with quercetin which contains the concentration of $100 \mu \mathrm{g} / \mathrm{ml}$. Further, $25 \mathrm{ml}$ of this solution was taken and made up to $100 \mathrm{ml}$ with quercetin which contains the concentration of $25 \mu \mathrm{g} / \mathrm{ml}$. Similarly, 50, 75, 100, 125, and $150 \mu \mathrm{g} / \mathrm{ml}$ concentrations of quercetin solution were prepared. Calibration curve was plotted by mixing $9.8 \mathrm{ml}$ aliquots of quercetin solutions with a $10 \%$ solution of aluminum chloride $(200 \mu \mathrm{l})$. The absorbance was measured $30 \mathrm{~min}$ at $425 \mathrm{~nm}$ using UV spectrophotometer, against the blank solution. ${ }^{[12-15]}$

\section{Antidepressant Activity}

All the rats were divided into the four groups; each group consisted of 6 animals. Group I received saline $2 \mathrm{ml} / \mathrm{kg}$ orally; Group II received imipramine $(10 \mathrm{mg} / \mathrm{kg})$ i.p.; and Group III and Group IV administered ethanol extracts of V. tessellate $200 \mathrm{mg} / \mathrm{kg}$ and $400 \mathrm{mg} / \mathrm{kg}$, respectively orally.

\section{Forced swim test (FST)}

For the FST, rats of either sex were individually forced to swim in an open cylindrical container (diameter $10 \mathrm{~cm}$ and height $25 \mathrm{~cm}$ ) containing $19 \mathrm{~cm}$ of water at $25 \pm 1{ }^{\circ} \mathrm{C}$. Treatment was given 60 min before study as described by 
study design. All animals were forced to swim for $6 \mathrm{~min}$, and the duration of immobility was observed and measured during the final $4 \mathrm{~min}$ interval of the test. Each animal was judged to be immobile when it ceased struggling and remained floating motionless in the water, making only those movements to keep its head above water. A decrease in the duration of immobility is indicative of an antidepressant-like effect.

\section{Tail suspension test (TST)}

Treatment was given 60 min before study as described by study design. Animals were suspended on the edge of the table, $50 \mathrm{~cm}$ above the floor, with the help of adhesive tape placed approximately $1 \mathrm{~cm}$ from the tip of the tail. The total duration of immobility induced by tail suspension was recorded during a $6 \mathrm{~min}$ of the $10 \mathrm{~min}$ period. Animal was considered to be immobile when it did not show any movement of the body, hanged passively, and completely motionless. ${ }^{[4]}$

\section{Statistical Analysis}

All the values were expressed as Mean \pm structural equation modeling; the results were analyzed statistically by one-way ANOVA followed by Dunnett Multiple comparison test, $P<0.05$ was considered significant.

\section{RESULTS AND DISCUSSION}

The plants consisting numerous biologically active compounds and are responsible for revealing various pharmacological activities. The active chemical constituents exhibiting antioxidant activity compounds are preferred more over synthetic ones due to safety concerns. The natural antioxidants have been shown to reduce the risk and progression of varied diseases such as cancer, depression disorders, liver cirrhosis, renal impairment, cardiovascular, hypertension, diabetes, and neurodegenerative diseases by scavenging free radicals through various biological mechanisms

In the present study, $V$. tessellate leaves were selected to evaluate the quantitative estimation of TPC and TFC and antidepressant activity of extracts.

\section{Antioxidant Activity}

\section{TPC of V. tessellata}

The chloroform and ethanol extracts of $V$. tessellate were assessed for exploration of the total phenolic content concentrations in extracts. Standard curve of gallic acid was calculated and plotted in distilled water for determining absorption data [Table 1]. The linear equation of gallic acid was found to be $\mathrm{y}=0.0042 \mathrm{x}-0.0029$ [Figure 1]. The total phenolic content of chloroform and ethanol extracts of $V$. tessellate were $98.25 \pm 0.11$ and $202.00 \pm 0.21$ GAE $\mathrm{mg} / \mathrm{gm}$, respectively [Table 2]. The ethanol extracts exhibited the highest amount of total polyphenol content compared to chloroform extracts.

The findings of TPC are similar to the data presented by Stanković (2011) for Marrubium peregrinum. It is reported that phenol components are highly soluble in polar solvent, namely ethanol and results of TPC justified it. ${ }^{[16]}$ Phenolic compounds are large and assorted group of plant metabolites that are known to display diverse biological activities, most of which are attributed to antioxidant activity.

\section{TFC of V. tessellata}

The content of flavonoids for chloroform and ethanol extracts of $V$. tessellate was expressed in terms of quercetin equivalents. Standard curve of quercetin was calculated and

\section{Table 1: Absorbance by gallic acid in different} concentration

\begin{tabular}{lc} 
Concentration & Absorbance \\
\hline 0 & 0 \\
25 & 0.101 \\
50 & 0.216 \\
75 & 0.315 \\
100 & 0.415 \\
125 & 0.512 \\
150 & 0.651 \\
\hline
\end{tabular}

Table 2: Estimation of total phenolic content of V. tessellata extract

Extracts

Total polyphenol content (GAE mg/gm)

Chloroform extract $\quad 98.25 \pm 0.11$

Ethanol extract $202.00 \pm 0.21$

GAE: Gallic acid equivalent

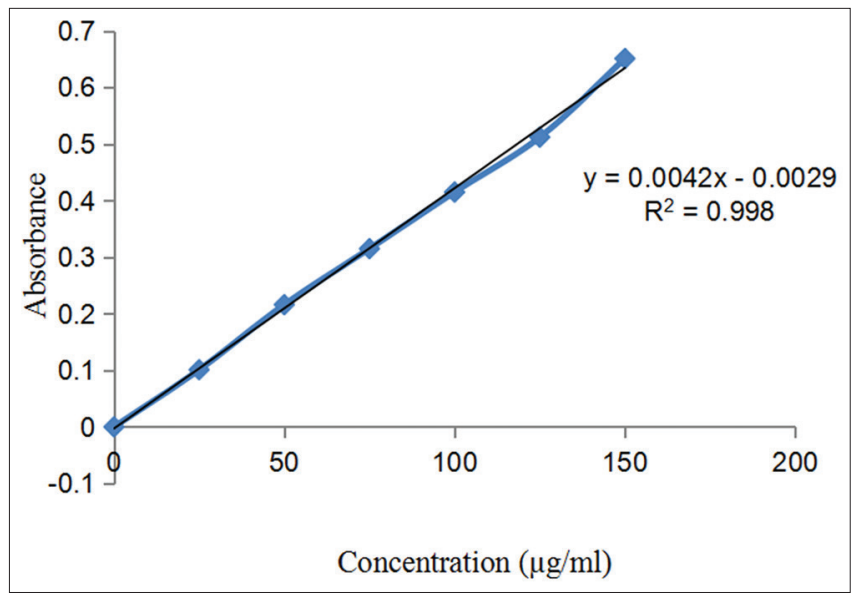

Figure 1: Calibration curve of gallic acid in distilled water 
plotted in distilled water for determining absorption data [Table 3]. The linear equation of quercetin was found to be $\mathrm{y}=0.0115 \mathrm{x}-0.0264$ [Figure 2]. The content of flavonoids in chloroform and ethanol extracts of $V$. tessellata is shown in Table 4. The concentrations of flavonoids in chloroform and ethanol extracts of $V$. tessellate were $23.57 \pm 0.47$ and $114.48 \pm 0.12 \mathrm{QE} \mathrm{mg} / \mathrm{gm}$, respectively. The ethanol extracts displayed the highest amount of flavonoids content compared to chloroform extracts. According to Min and Chun-Zhao (2005), the concentration of flavonoid in plant extract depends on the polarity of solvents. Hence, the maximum concentration of flavonoids was observed in ethanol extract. ${ }^{[17]}$

The polyphenol and flavonoids impart chief role in the eradication of free radicals from the body due to its antioxidant property. The antioxidant property of extract can be used for the prevention and cure of various diseases allied with free radicals. It has been reported that compounds such as the flavonoids, which contain hydroxyl, are responsible for the radical scavenging effects of most plants. The mechanism of action of the flavonoids is through scavenging or chelating processes. ${ }^{[15]}$

The primary findings of TPC and TFC of $V$. tessellata leaves extract demonstrated that extract possesses antioxidant activity and are able to produce antidepressant activity. The higher concentration of flavonoids and polyphenol was observed in ethanol extract compared to chloroform extracts. Hence, the ethanol extract of $V$. tessellata was elected for the investigation of antidepressant activity.

\section{Antidepressant Activity}

FST and TST are the most commonly used preliminary screening tests for illustrating potential antidepressant drugs.

\begin{tabular}{|c|c|}
\hline Concentration & Absorbance \\
\hline 0 & 0 \\
\hline 25 & 0.225 \\
\hline 50 & 0.558 \\
\hline 75 & 0.812 \\
\hline 100 & 1.139 \\
\hline 125 & 1.438 \\
\hline 150 & 1.681 \\
\hline
\end{tabular}

Table 4: Estimation of total flavonoid content of

V. tessellata extract

\begin{tabular}{lc} 
Extracts & Total flavonol content (QE $\mathbf{~ m g} / \mathbf{g m})$ \\
\hline Chloroform extract & $23.57 \pm 0.47$ \\
Ethanol extract & $114.48 \pm 0.12$ \\
\hline
\end{tabular}

FST

Table 5 exhibited the animals treated with the ethanol extract of V. tessellata at doses of $200 \mathrm{mg} / \mathrm{kg}$ and $400 \mathrm{mg} / \mathrm{kg}$ significantly decreased the immobility time of animal compared to the normal group in FST. The animals treated with imipramine $(10 \mathrm{mg} / \mathrm{kg})$ significantly decreased the immobility time of animals. The increase in the motor activity of animals which elevate depressed mood by decreasing immobility time of animals. The decreased in immobility time of animals in FST expressed the antidepressant-like activity.

\section{TST}

Table 6 demonstrated the animals treated with the ethanol extract of $V$. tessellata at doses of $200 \mathrm{mg} / \mathrm{kg}$ and $400 \mathrm{mg} / \mathrm{kg}$ significantly decreased the immobility time of animal compared to normal group in TST. The animals treated with imipramine $(10 \mathrm{mg} / \mathrm{kg})$ significantly decreased the immobility time of animals. The increase in the motor activity of animals which elevate depressed mood by decreasing immobility time of animals. The decreased in immobility time of animals in TST expressed the antidepressant-like activity.

The male animals were used to screen the potential antidepressant-like activity of the $V$. tessellata. The constraints observed in both model are immobility time of animals. The ethanol extract of $V$. tessellata reduced the immobility period during the forced swimming and TST in comparison with normal group and displayed a dosedependent antidepressant activity. The characteristic behavior evaluated in FST and TST, termed immobility, has been considered to reflect behavioral despair similar to that seen in the human depression, and hence any reduction in immobility time of animals reflects antidepressant activity ${ }^{[6]}$ Hence, the findings of ethanol extract of $V$. tessellata correlated with the above statements. Consequently, the findings showed that the ethanol extract of $V$. tessellata showed a significant dosedependent activity and offers good percentage protection as compared to normal group.

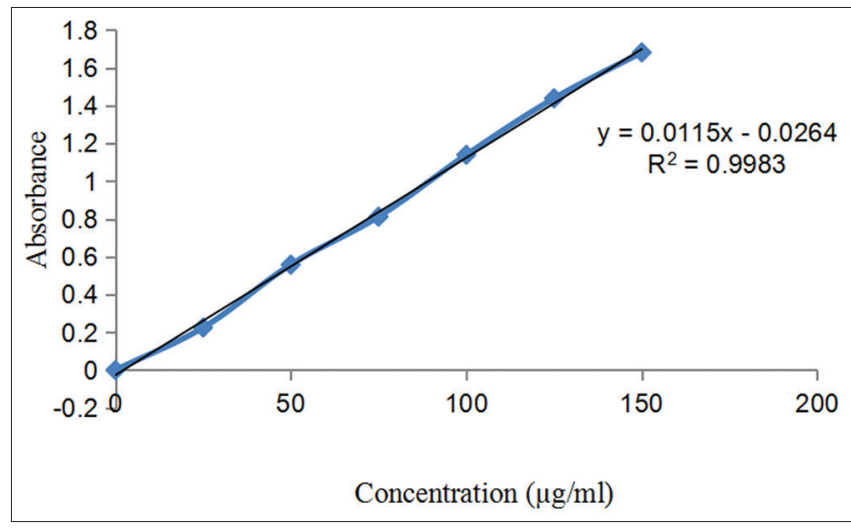

Figure 2: Calibration curve of quercetin in distilled water 
Table 5: Effect of ethanol extract of $V$. tessellata on immobility time in FST rats

\begin{tabular}{lcc} 
Groups & FST duration of immobility (Sec) & Percent reduction in time of immobility \\
\hline Normal & $192.27 \pm 2.63$ & - \\
Imipramine $(10 \mathrm{mg} / \mathrm{kg})$ & $69.15 \pm 4.71^{*}$ & 64.03 \\
Ethanol extracts of $V$. tessellata $200 \mathrm{mg} / \mathrm{kg}$ & $92.34 \pm 6.85^{\star}$ & 51.97 \\
Ethanol extracts of $V$. tessellate $400 \mathrm{mg} / \mathrm{kg}$ & $78.54 \pm 5.43^{*}$ & 59.15
\end{tabular}

Valuesexpressed as Mean \pm SEM, $n=6$ animals; ${ }^{*} P<0.05$ compared with normal groups, FST: Forced swimming test, $V$. tessellate: Vanda tessellata

\section{Table 6: Effect of ethanol extract of $V$. tessellata on immobility time in TST rats}

\begin{tabular}{lcc} 
Groups & TST duration of immobility (Sec) & Percent reduction in time of immobility \\
\hline Normal & $208.63 \pm 5.82$ & - \\
Imipramine $(10 \mathrm{mg} / \mathrm{kg})$ & $79.18 \pm 2.43^{*}$ & 62.04 \\
Ethanol extracts of $V$. tessellata $200 \mathrm{mg} / \mathrm{kg}$ & $115.41 \pm 4.17^{*}$ & 44.68 \\
Ethanol extracts of $V$. tessellate $400 \mathrm{mg} / \mathrm{kg}$ & $85.57 \pm 3.92^{*}$ & 58.98
\end{tabular}

Valuesexpressed as Mean \pm SEM, $n=6$ animals; ${ }^{*} P<0.05$ compared with normal groups, TST: Tail suspension test, SEM: Structural equation modeling, $V$. tessellata: Vanda tessellata

The oxidative stress characterizes imbalance between oxidationreduction reactions. This happens due to the reduced ability of the antioxidant defense system to efficiently eliminate the excess of the oxygen-derived species production, prompting the toxicity of oxygen and its detrimental effects. Further, it has been observed enhanced oxidative stress in patients suffering from depression. ${ }^{[18]}$ The polyphenol and flavonoids component scavenge the oxygen-derived species and play an important role in controlling the depressive disorders. The findings indicate that the antioxidant property of leaves of $V$. tessellata validates the antidepressant activity of the plant.

\section{CONCLUSION}

The result of the present study showed that TPC and TFC are found the maximum in ethanol extract of $V$. tessellata leaves. The highest antioxidant activity of $V$. tessellata leaves extract might be useful in preventing the progress of various oxidative conditions. The ethanol extracts of $V$. tessellata leaves demonstrated significant antidepressant activity. Further research will be carrying out in future to explore the potential and isolation of bioactive compounds responsible for the antidepressant activity.

\section{REFERENCES}

1. Saeed N, Khan MR, Shabbir M. Antioxidant activity total phenolic and total flavonoid contents of whole plant extracts Torilis leptophylla. BMC Complement Altern Med 2012;12:221.

2. Pour BM, Jothy SL, Latha LY, Chen Y, Sasidharan S. Antioxidant activity of methanol extracts of different parts of Lantana camara. Asian Pac J Trop Biomed 2012; 2:960-5.
3. Sylvie DD, Anatole PC, Cabral BP, Veronique PB. Comparison of in vitro antioxidant properties of extracts from three plants used for medical purpose in Cameroon: Acalypha racemosa Garcinia lucida Hymenocardia lyrata. Asian Pac J Trop Biomed 2014; 4 Suppl 2:S625-32.

4. Kumar BS, Lakshman K, Velmurugan C, Sridhar SM, Gopisetty S. Antidepressant activity of methanolic extract of Amaranthus spinosus. Basic Clin Neurosci 2014; 5:11-7.

5. Fekadu N, Shibeshi W, Engidawork E. Evaluation of the antidepressant-like activity of the crude extract and solvent fractions of Rosa abyssinica Lindley (Rosaceae) using rodent models of depression. Clin Exp Pharmacol 2016; 6:1-7.

6. Shashikumara S, Prathima C, Sibgatullah M. Evaluation of antidepressant activity of ethanolic extract of Alangium salviifolium (L F) Wangerin in Swiss albino mice. Biomed Pharmacol J 2017;10:154-66.

7. Sutar RC, Kasture SB, Kalaichelvan VK. Evaluation of antidepressant activity of leaf extracts of Holoptelea integri Folia (Roxb) planch in experimental animals. Int J Pharm Sci 2014;6:250-3.

8. Chowdhury MA, Rahman MM, Chowdhury MR, Uddin MJ, Sayeed MA, Hossain MA. Antinociceptive and cytotoxicactivities ofanepiphyticmedicinalorchid: Vanda tessellata Roxb. BMC Complement Altern Med 2014; 14:464.

9. Kumar PK, Subramoniam A, Pushpangadan P. Aphrodisiac activity of vanda tessellata (Roxb.) hook. Ex don extract male mice. Indian J Pharmacol 2000; 32:300-4.

10. Das S, Bhattacharya A, Bhattacharya AK. Active constituentsofVandaroxburghii. BrJIndianChemSoc 1967; 44:804-5.

11. Chawla AS, Sharma AK, Handa SS, Dhar KL. Chemical 
studies and anti-inflammatory activity of Vanda roxburghii roots. Indian J Pharm Sci 1992;54:159-61.

12. Singh P, Jain K, Khare S, Shrivastav P. Evaluation of phytochemical and antioxidant activity of Tridax procumbens extract. UK J Pharm Biosci 2017;5:41-7.

13. Nabi NG, Shrivastava M. Estimation of total flavonoids and antioxidant activity of Spilanthes acmella leaves. UK J Pharm Biosci 2016;4:29-34.

14. Roy A, Bhoumik D, Sahu RK, Dwivedi J. Phytochemical screening and antioxidant activity of Sesbania grandiflora leaves extracts. Asian J Res Pharm Sci 2014; 4:16-21.

15. Sarkar A, Tripathi VD, Sahu RK, Aboulthana WM. Evaluation of anti-inflammatory and anti-arthritis activity of isolated fractions from Bauhinia purpurea leaves extracts in rats. UK J Pharm Biosci 2017;5:47-58.

16. Mohsen MS, Ammar MA. Total phenolic contents and antioxidant activity of corn tassel extracts. Food Chem 2008;112:595-8.

17. Min G, Zhao CL. Comparison of techniques for the extraction of flavonoids from cultured cells of Saussurea medusa maxim. World J Microb Biotechnol 2005; 21:1461-63.

18. Shoeb A, Chowta M, Pallempati G, Rai A, Singh A. Evaluation of antidepressant activity of vanillin in mice. Indian J Pharmacol 2013;45:141-4.

Source of Support: Nil. Conflict of Interest: None declared. 